\section{Limitations of the study}

This is a small study with 16 participants. Attempts have been made to minimise sampling bias and to improve validity and relevance. Not all lesbian, gay, and bisexual practitioners are members of GLADD, and it was not possible to observe clinical encounters directly. I thank all participants and the GLADD committee and to Ian Hodges, Susan Ormrod, Kingsley Norton, Vincent Quinn, Benjamin Soares, and Fiona Warren for their help, support, and encouragement throughout this project.

Funding: This research was partially funded by the Foundation for the Scientific Study of Sexuality.

Competing interests: None declared.

Ethical approval: South East Multi-centre Research Ethics Committee.

General Medical Council, Intimate examinations. London: GMC, 2001

2 British Medical Association. Trust in the doctor/patient relationship: guidance for doctors and patients on professional boundaries. London: BMA, 1997.

Giuffre PA, Williams CL. Not just bodies: strategies for desexualising the physical examination of patients. Gender Soc 2000;14:457-82

physical examination of patients. Gender Soc 2000;14:457-82.
Bignell CJ. Chaperones for genital examination. BMJ 1999;319:137-8.

5 Torrance CJ, Das R, Allison MC. Use of chaperones in clinics for Torrance CJ, Das R, Allison MC. Use of chaperones in clinics
genitourinary medicine: survey of consultants. BMJ 1999;319:159-60.
Knowles R. A greater depth of understanding of the chaperone's role is necessary. BMJ 1999;319:137.

7 Challacombe CB. Do women patients need women doctors? Practitioner 1983;227:848-50.

8 O'Flynn N, Rymer J, Wass V. Women's attitudes to the sex of medical students in a gynaecology clinic: cross sectional survey [with commentary]. BMJ 2002;325:683-4.

9 Coldicott Y, Pope C, Roberts C. The ethics of intimate examinationsteaching tomorrow's doctors. BMJ 2003;326:97-101.

10 Beauchamp TC. Principles of biomedical ethics. 5th ed. New York: Oxford University Press, 2001.

11 Lewis RJ, Derlega VJ, Berndt A, Morris ML, Rose S. An empirical analysis of stressors for gay men and lesbians. J Homosexuality 2001:42:63-88.

Department of Trade and Industry. The employment equality (sexual orientation) regulations. London: DTI, 2003.

13 Gay and Lesbian Association of Doctors and Dentists. Improving working lives. London: GLADD, 2002.

14 Risdon C, Cook D, Willms D. Gay and lesbian physicians in training: a qualitative study. CMAJ 2000;162:331-4.

15 Advisory, Conciliation and Arbitration Service. Sexual orientation discrimination regulations. London: ACAS, 2003.

16 Selby M. Ethical dilemma: dealing with racist patients [with commentaries]. BMJ 1999;318:1129-31.

17 Moynihan C. Theories in health care and research: theories of masculinity. BMJ 1998;317:1072-5.

18 Doyal L. Sex, gender, and health; the need for a new approach. BMJ 2001;323:1061-3.

19 Hughes C, Evans A. Health needs of women who have sex with women. BMJ 2003;327:939-40.

(Accepted 11 February 2004)

doi 10.1136/bmj.38071.774525.EB

\title{
Representation of authors and editors from countries with different human development indexes in the leading literature on tropical medicine: survey of current evidence
}

\author{
Jennifer Keiser, Jürg Utzinger, Marcel Tanner, Burton H Singer
}

\begin{abstract}
Objective To assess the current international representation of members of editorial and advisory boards and authors in the leading peer reviewed literature on tropical medicine.

Design Systematic review.

Main outcome measures Country affiliations, as classified by the human development index, of editorial and advisory board members of all tropical medicine journals referenced by the Institute of Scientific Information (ISI) as of late 2003 and of all contributing authors of full articles published in the six leading journals on tropical medicine in 2000-2. Results Sixteen $(5.1 \%)$ of the 315 editorial and advisory board members from the 12 ISI referenced journals on tropical medicine are affiliated to countries with a low human development index and $223(70.8 \%)$ to countries with a high index. Examination of the 2384 full articles published in 2000-2 in the six highest ranking tropical medicine journals showed that $48.1 \%$ of contributing authors are affiliated to countries with a high human development index, whereas the percentage of authors from countries with a low index was 13.7\%. Articles written exclusively by authors from low ranked countries accounted for $5.0 \%$. Our data indicate that research collaborations between a country with a high human development index and one that has either a medium or a low index are
\end{abstract}

common and account for $26.5 \%$ and $16.1 \%$ of all full articles, respectively.

Conclusion Current collaborations should be transformed into research partnerships, with the goals of mutual learning and institutional capacity strengthening in the developing world.

\section{Introduction}

Serious under-representation of editorial and advisory board members from countries with a low human development index in general medical and psychiatry journals has been documented recently. ${ }^{12}$ In addition, very low proportions of published articles from authors from low income countries have been found in many research fields, including psychiatry, ${ }^{3}$ cardiovascular disease, ${ }^{4}$ and epidemiology and HIV/AIDS. ${ }^{5}$

The current global burden of infectious and parasitic diseases is heavily concentrated in the developing world. ${ }^{6}$ Major national and international initiatives have been launched to improve research capacities in developing countries. ${ }^{7}$ It is therefore interesting to investigate whether scientists affiliated to countries with low or medium human development indexes have more dominant roles in the research and control of tropical diseases than in other fields and hence share their experiences and disseminate their findings in the peer

This article was posted on bmj.com on 1 April 2004: http://bmj.com/cgi/ doi/10.1136/bmj.38069.518137.F6
Office of Population Research, Princeton University, Princeton, N 08544, USA

Jennifer Keiser research fellow Jürg Utzinger visiting research fellow

Burton H Singer professor

Swiss Tropical Institute, PO Box, CH-4002 Basle, Switzerland Marcel Tanner professor

Correspondence to J Keiser jennifer.keiser@ unibas.ch

BMJ 2004;328:1229-32 
Table 1 Characteristics of all 12 tropical medicine journals that are referenced by the Institute of Scientific Information (ISI)

\begin{tabular}{|c|c|c|c|c|c|c|}
\hline \multirow[b]{2}{*}{ Journal } & \multirow{2}{*}{$\begin{array}{l}\text { Impact factor in } \\
2002^{*}\end{array}$} & \multirow{2}{*}{$\begin{array}{l}\text { No of members of } \\
\text { editorial and } \\
\text { advisory board }\end{array}$} & \multicolumn{3}{|c|}{$\begin{array}{l}\text { No (\%) of members of editorial and advisory } \\
\text { board stratified by ranking of countries of current } \\
\text { affiliation on human development index }\end{array}$} & \multirow[b]{2}{*}{ Location of head office } \\
\hline & & & High & Medium & Low & \\
\hline $\begin{array}{l}\text { American Journal of Tropical } \\
\text { Medicine and Hygiene }\end{array}$ & 2.063 & $17 \dagger$ & $15(88.2)$ & $2(11.8)$ & $0(0)$ & Ohio, United States \\
\hline $\begin{array}{l}\text { Tropical Medicine and } \\
\text { International Health }\end{array}$ & 1.796 & $29 \dagger$ & $24(82.8)$ & $3(10.3)$ & $2(6.9)$ & London, United Kingdom \\
\hline $\begin{array}{l}\text { Transactions of the Royal Society } \\
\text { of Tropical Medicine and } \\
\text { Hygiene }\end{array}$ & 1.742 & $23 \dagger$ & $23(100)$ & $0(0)$ & $0(0)$ & London, United Kingdom \\
\hline Acta Tropica & 1.332 & $27 \dagger$ & $22(81.5)$ & $4(14.8)$ & $1(3.7)$ & Stockholm, Sweden \\
\hline Leprosy Review & 1.017 & $11 \dagger$ & $11(100)$ & $0(0)$ & $0(0)$ & Colchester, United Kingdom \\
\hline $\begin{array}{l}\text { Annals of Tropical Medicine and } \\
\text { Parasitology }\end{array}$ & 0.978 & $47 \ddagger$ & $38(80.9)$ & $5(10.6)$ & $4(8.5)$ & Liverpool, United Kingdom \\
\hline $\begin{array}{l}\text { International Journal of Leprosy } \\
\text { and Other Mycobacterial } \\
\text { Diseases }\end{array}$ & 0.963 & $21 \dagger$ & $11(52.3)$ & $9(42.9)$ & $1(4.8)$ & Baton Rouge, United States \\
\hline $\begin{array}{l}\text { Memorias do Instituto Oswaldo } \\
\text { Cruz }\end{array}$ & 0.635 & $68 \ddagger$ & $33(48.5)$ & $35(51.5)$ & $0(0)$ & Rio de Janeiro, Brazil \\
\hline Annals of Tropical Paediatrics & 0.429 & $23 \ddagger$ & $12(52.2)$ & $7(30.4)$ & $4(17.4)$ & Liverpool, United Kingdom \\
\hline Journal of Tropical Pediatrics & 0.413 & $7 \S$ & $4(57.1)$ & $3(42.9)$ & $0(0)$ & Oxford, United Kingdom \\
\hline Tropical Doctor & 0.330 & $19 \ddagger$ & $9(47.3)$ & $7(36.8)$ & $3(15.8)$ & London, United Kingdom \\
\hline $\begin{array}{l}\text { Bulletin de la Societé de } \\
\text { Pathologie Exotique }\end{array}$ & 0.236 & $23 \dagger$ & $21(91.3)$ & $1(4.3)$ & $1(4.3)$ & Paris, France \\
\hline Total & & 315 & $223(70.8)$ & $76(24.1)$ & $16(5.1)$ & \\
\hline
\end{tabular}

${ }^{*}$ Source ISI Web of Science.

†Editorial boards.

łEditorial and advisory boards.

$\S$ Editors and associate regional editors.

reviewed international literature. We systematically reviewed and discussed the current geographical composition of editorial and advisory boards and of contributing authors in the literature on tropical medicine as classified by the human development index.

\section{Material and methods}

In July 2003 we systematically analysed the geographical composition of the editorial and advisory boards of all 12 journals indexed under the category "tropical medicine" in the journal citation reports of the Institute of Scientific Information (ISI), by visiting the journals' electronic homepages and studying the latest print issues. We noted board members' country affiliations as classified by the human development index 2002. This is a cumulative measure of the achievements of an individual country in terms of their residents' life expectancy, educational attainment, and adjusted real income. Countries have been classified by high, medium, and low human development (http:// hdr.undp.org/). We also recorded the geographical location of the editorial office (town and country) of the same 12 journals.

We then selected the six leading journals on the basis of their impact factors for 2002, namely the American Journal of Tropical Medicine and Hygiene (impact factor 2.063), Tropical Medicine and International Health (1.796), Transactions of the Royal Society of Tropical Medicine and Hygiene (1.742), Acta Tropica (1.332), Leprosy Review (1.017), and Annals of Tropical Medicine and Parasitology (0.978). We carried out a retrospective analysis for 2000-2 with particular consideration of the country affiliation of all contributing authors (hereafter "author countries"). We included all full articles but excluded editorials, letters to the editor, conference proceedings or reports, special reports, teaching materials, reviews of books and CDs, and news announcements. We noted author countries of all, first, and last contributors according to a low, medium, and high human development index. We omitted articles that lacked authors' address details for unambiguous linkage $(<0.5 \%, \mathrm{n}=11)$. Authors with double or triple addresses that resulted in different rankings were accounted for as half or one third under the index category.

\section{Results}

\section{Editorial boards}

Table 1 summarises the current geographical affiliations, ranked by human development index, of all 315 members of editorial and advisory boards from the 12 tropical medicine journals currently referenced by the ISI. Overall, $223(70.8 \%)$ of all board members are from countries with a high human development index. Only $16(5.1 \%)$ board members are affiliated with countries with a low index; eight of them are on the boards of only two journals (Annals of Tropical Medicine and Parasitology, $\mathrm{n}=4$; Annals of Tropical Paediatrics, $n=4$ ). Five of the journals do not have any representatives from a country with a low human development index on their boards, and three have only one representative. With the exception of the Brazil based Memorias do Instituto Oswaldo Cruz $(\mathrm{n}=35)$, only 41 members of the remaining journals have affiliations to countries with a medium index, most notably on International Journal of Leprosy and Other Mycobacterial Diseases $(\mathrm{n}=9)$, Tropical Doctor $(\mathrm{n}=7)$, and Annals of Tropical Paediatrics $(\mathrm{n}=7)$. For journals that not only have an editorial but also an advisory board (table 1) the composition of the boards is more geographically balanced than for journals with only an editorial board (such as Annals of Tropical Paediatrics). Except for the editorial office of the Memorias do Instituto Oswaldo $\mathrm{Cruz}$, all other ISI referenced tropical medicine journals are based in the United States $(n=2)$ or in 
Table 2 Country affiliations as classified by the human development index of all, first, and last authors of all full articles published in 2000-2 in the six leading tropical medicine journals. Source ISI Web of Science

\begin{tabular}{|c|c|c|c|c|c|c|c|c|c|c|c|}
\hline \multirow[b]{2}{*}{ Journal } & \multirow[b]{2}{*}{$\begin{array}{l}\text { No of articles } \\
\text { analysed }^{*}\end{array}$} & \multirow{2}{*}{$\begin{array}{l}\text { No of } \\
\text { contributing } \\
\text { authors }\end{array}$} & \multicolumn{3}{|c|}{ All authors† } & \multicolumn{3}{|c|}{ First authors $\ddagger$} & \multicolumn{3}{|c|}{ Last authorsł } \\
\hline & & & High (\%) & $\begin{array}{l}\text { Medium } \\
(\%)\end{array}$ & Low (\%) & High (\%) & $\begin{array}{l}\text { Medium } \\
(\%)\end{array}$ & Low (\%) & High (\%) & $\begin{array}{l}\text { Medium } \\
(\%)\end{array}$ & Low (\%) \\
\hline $\begin{array}{l}\text { American Journal of } \\
\text { Tropical Medicine } \\
\text { and Hygiene }\end{array}$ & 638 & 4197 & 55.9 & 38.0 & 6.1 & 59.8 & 35.7 & 4.5 & 66.5 & 29.4 & 4.1 \\
\hline $\begin{array}{l}\text { Tropical Medicine and } \\
\text { International Health }\end{array}$ & 398 & 2041 & 47.6 & 26.4 & 26.0 & 53.9 & 24.1 & 22.0 & 65.4 & 20.3 & 14.3 \\
\hline $\begin{array}{l}\text { Transactions of the } \\
\text { Royal Society of } \\
\text { Tropical Medicine } \\
\text { and Hygiene }\end{array}$ & 538 & 2840 & 45.6 & 38.5 & 15.9 & 47.5 & 38.6 & 13.9 & 58.3 & 32.2 & 9.5 \\
\hline Acta Tropica & 349 & 1654 & 42.5 & 48.5 & 9.0 & 46.3 & 44.3 & 9.4 & 53.0 & 39.1 & 7.9 \\
\hline Leprosy Review & 155 & 519 & 38.6 & 46.2 & 15.2 & 45.5 & 38.4 & 16.1 & 47.4 & 37.4 & 15.2 \\
\hline $\begin{array}{l}\text { Annals of Tropical } \\
\text { Medicine and } \\
\text { Parasitology }\end{array}$ & 306 & 1486 & 40.6 & 40.6 & 18.8 & 40.2 & 44.1 & 15.7 & 46.9 & 40.4 & 12.7 \\
\hline$\overline{\text { Total }}$ & 2384 & 12737 & 48.1 & 38.2 & 13.7 & 50.6 & 36.9 & 12.5 & 58.8 & 31.8 & 9.4 \\
\hline
\end{tabular}

${ }^{*}$ For inclusion criteria see materials and methods section.

†Based on the number of all authors in each journal.

$\ddagger$ Based on the number of all articles in each journal.

Europe $(n=9)$, particularly in the United Kingdom $(\mathrm{n}=7)$.

\section{Author representation according to human development index}

We examined 2384 articles published in the six highest ranking journals on tropical medicine in 2000-2. Single authored publications were rare $(6.8 \%, \mathrm{n}=162)$. The median number of authors per article is five, and the maximum number of coauthors on a single paper was 35 .

Table 2 presents the geographical affiliations of authors according to the human development index. Overall the proportion of authors affiliated with countries with a high human development index is 48.1\% (range $38.6 \%$ (Leprosy Review) to $55.9 \%$ (American Journal of Tropical Medicine and Hygiene)). The proportions of first and last authors from countries with a high index are even higher, namely $50.6 \%$ (range $40.2-59.8 \%$ ) and 58.8\% (range 46.9-66.5\%), respectively. Annals of Tropical Medicine and Parasitology had the lowest percentages of first and last authors from countries with a high index, and the American Journal of Tropical Medicine and Hygiene had the highest percentages. We observed a positive trend between the percentages of first, last, and all authors from countries with a high human development index with the impact factor of a journal.

The percentages of authors from countries with a low human development index range from as low as 6.1\% (American Journal of Tropical Medicine and Hygiene) to a maximum of $26.0 \%$ (Tropical Medicine and International Health). They decrease to $4.5 \%$ and $22.0 \%$ for these two journals respectively if only the first authors, and to 4.1\% (American Journal of Tropical Medicine and Hygiene) and $15.2 \%$ (Leprosy Review) if only the last authors are considered.

Table 3 shows the current extent of research collaborations between countries with different rankings on the human development index and the number and percentage of articles from countries with the same rankings. The percentage of articles published exclusively by authors from countries with a low index ranges from 1.7\% (American Journal of Tropical Medicine and Hygiene) to $7.7 \%$ (Leprosy Review). In contrast, far higher proportions of authors from countries with a high index have published their work exclusively in leading tropical medicine journals, from 20.9\% (Annals of Tropical Medicine and Parasitology) at the low end of the scale to 35.9\% (American Journal of Tropical Medicine and Hygiene)

Table 3 Extent of research collaborations between countries with different rankings on the human development index. Values are numbers $(\%)$ of articles

\begin{tabular}{|c|c|c|c|c|c|c|c|c|}
\hline \multirow[b]{2}{*}{ Journal } & \multicolumn{4}{|c|}{ Country's human development index } & \multirow{2}{*}{$\begin{array}{l}\text { Total no of } \\
\text { articles from } \\
\text { research } \\
\text { collaborations* }\end{array}$} & \multicolumn{3}{|c|}{$\begin{array}{l}\text { Exclusively from authors in countries with } \\
\text { human development index ranking }\end{array}$} \\
\hline & High and low & $\begin{array}{l}\text { High and } \\
\text { medium }\end{array}$ & $\begin{array}{l}\text { Medium and } \\
\text { low }\end{array}$ & $\begin{array}{l}\text { High, medium, } \\
\text { and low }\end{array}$ & & High & Medium & Low \\
\hline $\begin{array}{l}\text { American Journal of } \\
\text { Tropical Medicine } \\
\text { and Hygiene }\end{array}$ & $54(8.5)$ & $205(32.1)$ & $0(0)$ & $12(1.9)$ & $271(42.5)$ & $229(35.9)$ & $127(19.9)$ & 11 (1.7) \\
\hline $\begin{array}{l}\text { Tropical Medicine and } \\
\text { International Health }\end{array}$ & 114 (28.6) & $113(28.4)$ & $4(1.0)$ & 9 (2.3) & $240(60.3)$ & 88 (22.1) & $43(10.8)$ & $27(6.8)$ \\
\hline $\begin{array}{l}\text { Transactions of the } \\
\text { Royal Society of } \\
\text { Tropical Medicine } \\
\text { and Hygiene }\end{array}$ & 116 (21.6) & $155(28.8)$ & $1(0.2)$ & $9(1.7)$ & $281(52.2)$ & $121(22.5)$ & $110(20.4)$ & $26(4.8)$ \\
\hline Acta Tropica & $30(8.6)$ & $86(24.6)$ & $0(0)$ & $5(1.4)$ & $121(34.7)$ & $105(30.1)$ & $102(29.2)$ & $21(6.0)$ \\
\hline Leprosy Review & $24(15.5)$ & $13(8.4)$ & $0(0)$ & $2(1.3)$ & $39(25.2)$ & $52(33.5)$ & $52(33.5)$ & $12(7.7)$ \\
\hline $\begin{array}{l}\text { Annals of Tropical } \\
\text { Medicine and } \\
\text { Parasitology }\end{array}$ & 45 (14.7) & 60 (19.6) & 4 (1.3) & 9 (2.9) & $118(38.6)$ & $64(20.9)$ & $102(33.3)$ & $22(7.2)$ \\
\hline Total & 383 (16.1) & 632 (26.5) & $9(0.4)$ & $46(1.9)$ & $1070(44.9)$ & $659(27.6)$ & $536(22.5)$ & $119(5.0)$ \\
\hline
\end{tabular}

*Defined as articles including authors from countries with high and low human development index, high and medium index, medium and low index, or all three. 


\section{What is already known on this topic}

Strengthening of research capacity from developing countries is essential to reduce inequities in health

Few scientists from countries with a low human development index serve on editorial and advisory boards of leading international journals

Authors from countries with a low development index are under-represented in numerous research fields (for example, general medicine)

\section{What this study adds}

An imbalance of international representation exists among editorial and advisory boards of the ISI referenced journals on tropical medicine

Only $1.7-7.7 \%$ of the articles published in the six leading tropical medicine journals in 2000-2 were generated exclusively by scientists from countries with a low human development index

International research collaborations (mainly between a country with a low or medium human development index and Europe or the United States) are common in tropical medicine

Collaborations should be transformed into research partnerships to enhance mutual learning and institutional capacity building

at the high end. Over the investigated period of three years we found a high percentage of articles originating exclusively from countries with a medium index (33.3\% for Annals of Tropical Medicine and Parasitology and 33.5\% for Leprosy Review).

The total proportion of research collaborations between countries with different human development indexes ranges from 25.2\% (Leprosy Review) to $60.3 \%$ (Tropical Medicine and International Health) of all full articles. Research collaborations between authors from countries with a high and medium index were more common (26.5\%) than between authors from countries with high and low indexes (16.1\%). Research collaborations between authors either from countries with all three rankings or from countries with medium and low indexes were uncommon, at $1.9 \%$ and $0.4 \%$, respectively.

\section{The way forward}

Our analyses extend recent findings of imbalanced editorial and advisory boards of general medical and psychiatry journals ${ }^{12}$ to the literature on tropical medicine. As potential remedies the establishment of regional offices, the inclusion of internationally representative members in advisory boards, or the creation of virtual platforms of exchange-for example, facilitated through enhanced internet access or video conferencing-should be considered. "Twinning" arrangements, as recently established between editors of five Western (including the $B M J$ ) and four African medical journals to establish mentoring relationships, will help in the training of editors from countries with a low human development index.

Our quantitative assessment of author representations on published full articles in 2000-2 in the six highest ranking tropical medicine journals shows that the number of articles generated exclusively by scientists from countries with a low human development index is marginal (1.7-7.7\%). We were surprised that authors from these countries were so drastically underrepresented in tropical medicine. However, $16.1 \%$ of all full articles originated from international research collaborations between a country with a low human development index and a country with a high index, another $26.5 \%$ between a country with a medium index and one with a high index, and 1.9\% among countries with all three rankings. Although the research agenda in the developing world may be dictated to some extent by the richer countries (also indicated by the high percentage of first and last authors as geographically ranked by high human development index), genuine research partnerships are an important mechanism for creating a conducive and stimulating environment for sound research in developing countries. Sustainable research partnerships that are built on mutual trust, shared information, and joint responsibilities enable exchange and transfer of technology and capacity building of local scientists. ${ }^{8}$ Such partnerships may also make it possible for researchers in countries with a low human development index to be helped in analysing, presenting, and discussing the data. In addition to the promotion of partnerships between developed and developing countries, the results of a poll on the $B M J$ website found the allocation of $2-5 \%$ of the health budget to research, the cutting of links between donor aid and decisions about research priorities, and the improvement of telecommunications to be the four most important strategies to improve research in poor countries. ${ }^{9}$

With adequate support-including sufficient funding-and sustained commitment the structure and emphasis of tropical medicine research can be transformed so that researchers from developing countries are leading the programmes in response to their local needs. This in turn might be a key factor in reducing the intolerable burden of infectious and parasitic diseases that continue to affect poor people worldwide disproportionately and might consequently be an important strategy towards alleviating poverty.

We thank Elana Broch and Mary Waltman for useful discussions, Giovanna Raso for her help in obtaining copies of the published articles, and Keith Wallbanks for his constructive external peer review.

Contributors: JK and JU had the idea for this study and designed the protocols for data collection. JK analysed the data and wrote the first draft of the manuscript. JU contributed to the analysis and writing of the paper. MT and BHS participated in structuring and revising the manuscript. JK is the guarantor.

Funding: None.

Competing interests: None declared.

1 Horton R. Medical journals: evidence of bias against the diseases of poverty. Lancet 2003;361:712-3.

Saxena S, Levav I, Maulik P, Saraceno B. How international are the editorial boards of leading psychiatry journals? Lancet 2003;361:609.

Patel V, Sumathipala A. International representation in psychiatric literature: survey of six leading journals. Br J Psychiatry 2001;178:406-9.

4 Mendis S, Yach D, Bengoa R, Narvaez D, Zhang X. Research gap in cardiovascular disease in developing countries. Lancet 2003;361:2246-7. Yach D, Kenya P. Assessment of epidemiological and HIV/AIDS publicaYach D, Kenya P. Assessment of epidemiologica
tions in Africa. Int J Epidemiol 1992;21:557-60.

Ezzati M, Lopez AD, Rodgers A, Vander Hoorn S, Murray CJM. Comparative risk assessment collaborating group. Selected major risk factors and global and regional burden of disease. Lancet 2002;360:1347-60.

7 Sitthi-Amorn C, Somrongthong R. Strengthening health research capacity in developing countries: a critical element for achieving health equity. BMJ 2000;321:813-7.

Harris F Tanner M. Health technology transfer BMJ 2000·321·817-20.

9 Smith R. Publishing research from developing countries. Stat Med 2002;21:2869-77.

(Accepted 4 February 2004)

doi 10.1136/bmj.38069.518137.F6 